\title{
Effect of Turn Region Treatments on the Pressure Loss Distribution in a Smooth Square Channel with Sharp $180^{\circ}$ Bend
}

\author{
D. V. Ratna Rao, Chakka Sarat Babu, and S. V. Prabhu \\ Indian Institute of Technology, Bombay, India
}

An experimental investigation is carried out to study the effect of several turn treatments like single guide vane (short and long) and multiple guide vanes on the pressure drop distribution in a square cross-sectioned smooth channel with a sharp $180^{\circ}$ bend. The sharp $180^{\circ}$ turn is obtained by dividing a rectangular passage into two square channels using a divider wall with a rounded tip at the location where the flow negotiates the turn. The study is carried out for a divider wall thickness to hydraulic diameter (W/D) of 0.2 for Reynolds numbers of 13,500 and 17,000 . The pressure drop distribution normalized with the mainstream fluid dynamic pressure head is presented for the outer surfaces. The results indicate that the shape and position of the guide vanes significantly affect the pressure losses associated with coolant flows through a sharp $180^{\circ}$ bend. Properly shaped $180^{\circ}$ vanes located in the center of the bend decrease the overall pressure drop by as much as $40-45 \%$ compared to the no guide vane within the bend.

Keywords $180^{\circ}$ bend, Guide vane, Pressure loss, Gas turbine blade cooling passage, Friction factor

\section{INTRODUCTION}

In advanced gas turbine engine designs, increased speeds, pressures, and temperatures are used to increase thrust/weight ratios and reduce the specific fuel consumption. Hence, the turbine blades are subjected to the loads resulting from the centripetal acceleration field of the order of $10^{4} \mathrm{~g}$, while simultaneously exposed to thermal environments hot enough to cause the

Received 17 September 2002; accepted 22 February 2003.

Address correspondence to Dr. S. V. Prabhu, Department of Mechanical Engineering, Indian Institute of Technology, Bombay, Powai400076, India. E-mail: svprabhu@me.iitb.ac.in

blade material to glow red (Metzger et al., 1984). High pressure air from the compressor introduced through the hub section into the blade interior helps in cooling the blade and keeping the blade material below the metallurgically permissible temperature limits. The cooling air flows through a complicated serpentine passage inside the blade that comprises of several channels along the blade height with the adjacent channels connected by sharp $180^{\circ}$ bends. A typical cooling passage can, therefore, be modeled as a straight smooth square channel with a sharp $180^{\circ}$ bend. The total coolant flow rate depends on the flow resistances within the cooling passages themselves. The design of the cooling passage requires detailed knowledge of the pressure loss characteristics of all the passage geometries to be considered in the design. Also, the pressures available to drive the required amounts of coolant flows through a particular passage are often small, thus the engine designer is interested in configuring passages so that the flow resistance is minimized so that the coolant flow rate will be increased. Increased coolant flow rates generally produce higher convection heat transfer coefficients and smaller streamwise increases in the coolant mixed mean temperature, both of which improve the cooling performance (Metzger et al., 1984).

The flow field and pressure drop characteristics in the sharp $180^{\circ}$ bends encountered in gas turbine blade cooling passages can be significantly different from those in the long radius bends. Metzger et al. (1984) studied the effects of channel geometry such as the before-turn and after-turn channel aspect ratio, the turn clearance, and flow Reynolds number on the pressure drop distribution. They concluded that both the channel aspect ratio and turn clearance have an important influence on the pressure drop characteristics of two-pass smooth rectangular channels. Liou et al. (1999) investigated the effect of divider wall thickness on the fluid flow in a two-pass smooth square duct with a $180^{\circ}$ straight corner turn. They found that the divider wall thickness has profound effects on the flow features inside and immediately after the turn. They observed that the turbulence level and uniformity in the region immediately after the turn 
decrease and increase with the increasing divider wall thickness. Son et al. (2002) carried out PIV experiments to measure the detailed average velocity distributions and turbulent kinetic energy for both the main and secondary flows in a two-pass square channel with a smooth wall and a $90^{\circ}$ rib roughened wall. PIV measurement results were compared with the heat transfer experimental data of Ekkad and Han (1997). Their study indicates that the flow impingement is the primary factor for the two-pass square channel heat transfer enhancement rather than the flow turbulence level itself.

Metzger and Plevich (1990) conducted an experimental study to evaluate the effect of geometric turn region inserts on pressure losses for flow through a sharp $180^{\circ}$ channel with $90^{\circ}$ ribs. Various turn region treatments studied include corner fillets, radial ribs, and turning vanes. The results show that the inclusion of turning vane reduces the pressure drop losses associated with the coolant flows through sharp $180^{\circ}$ turns. Little information is available in the open literature on the decrease of flow resistance in smooth channels with a sharp $180^{\circ}$ bend by inserting single and multiple guide vanes. The main objective of the present work is to study the effect of single (short and long) guide vane and multiple guide vanes of different configurations placed at different locations within the bend on the local and overall pressure drop distributions in a two-pass square smooth passage with a sharp $180^{\circ}$ bend for a divider wall thickness to hydraulic diameter $(W / D)$ ratio of 0.2. Experiments are conducted for Reynolds numbers varying from 13,500 and 17,000 with water as the working medium.

\section{EXPERIMENTAL SET-UP}

A schematic diagram of the experimental set-up is shown in Figure 1. Water is used as the working medium and a large rectangular tank of about 200 litre capacity serves as a storage

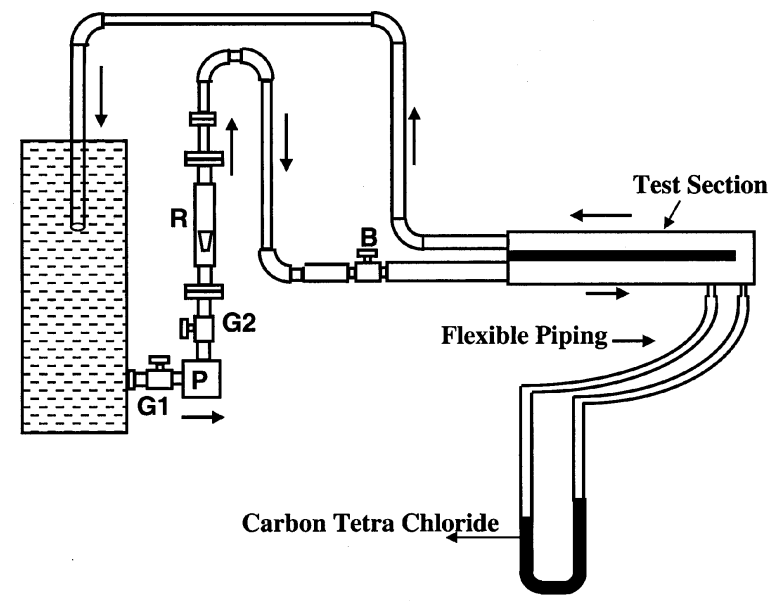

G1,G2 - Gate valve, B - Ball valve, P-Centrifugal pump, R - Rotameter, M - Manometer

FIGURE 1

Schematic of the experimental set-up.

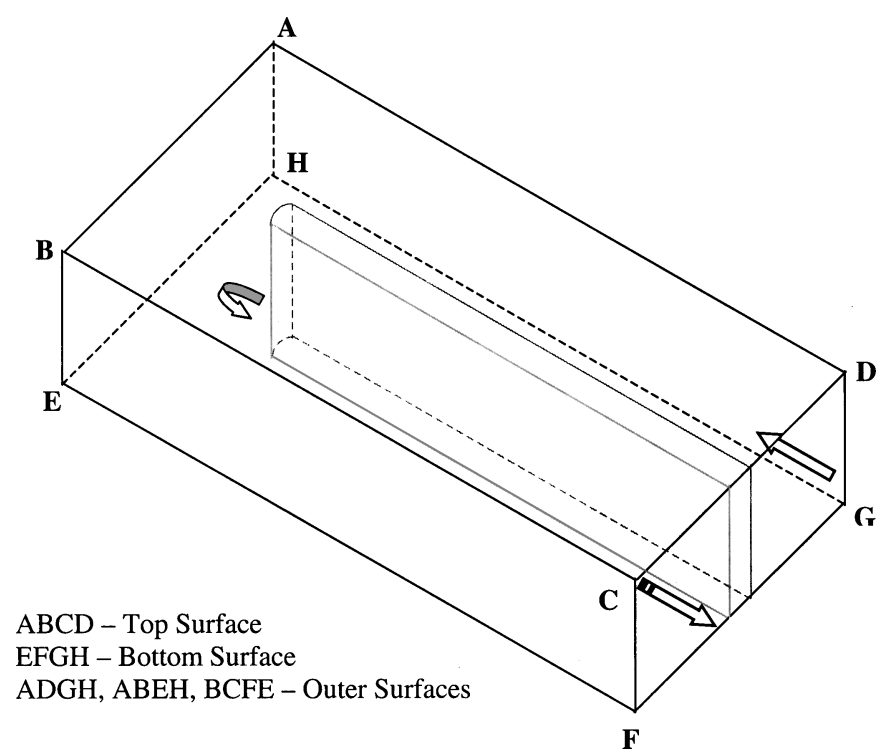

FIGURE 2

Three-dimensional view of the test section.
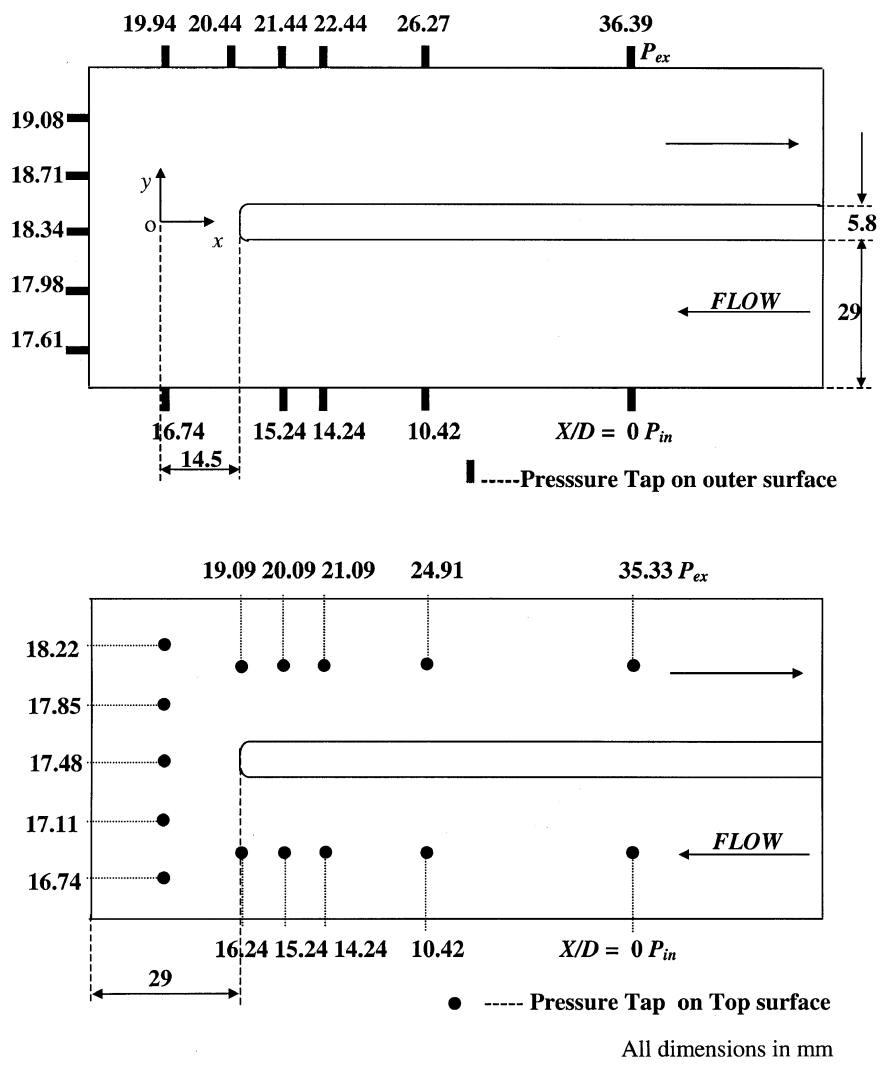

FIGURE 3

Schematic of the sharp cornered $180^{\circ}$ bend indicating the pressure tap locations on the outer and top surfaces. 


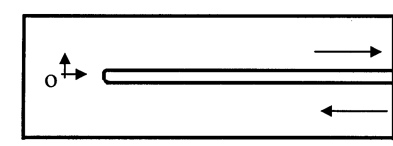

Ca :-1

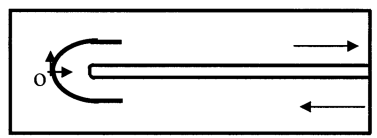

Case $-\mathbf{3}$

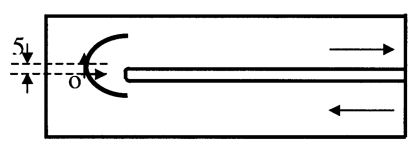

Case - 5
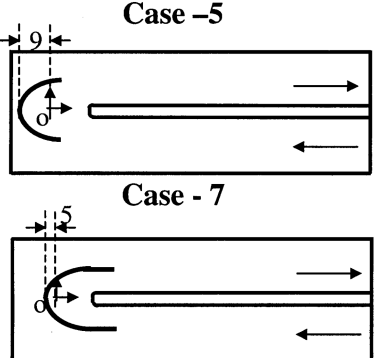

Case -9

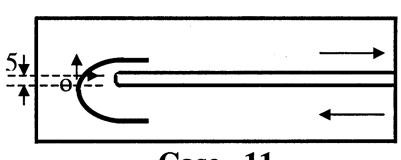

Case -11

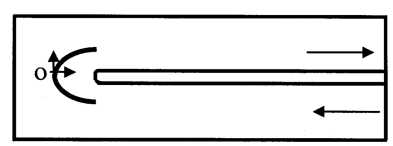

Case -2

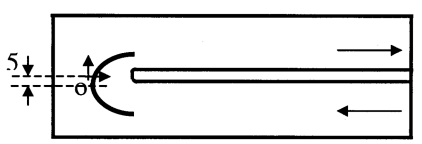

Case -4
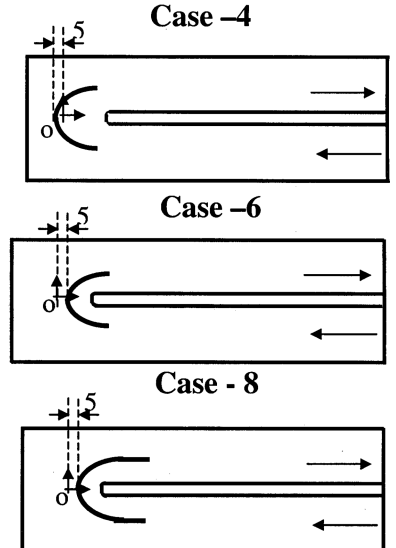

Case -10

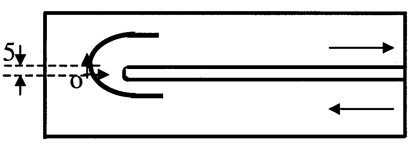

Case - 12

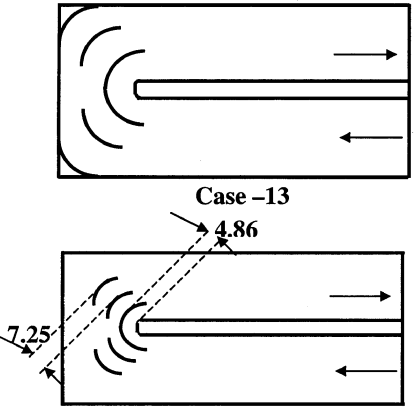

Case - 15

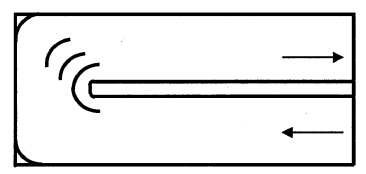

Case - 17

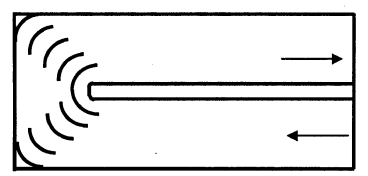

Case - 19

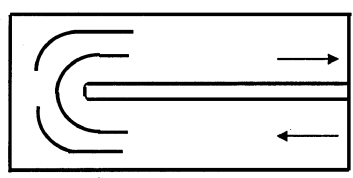

Case - 21

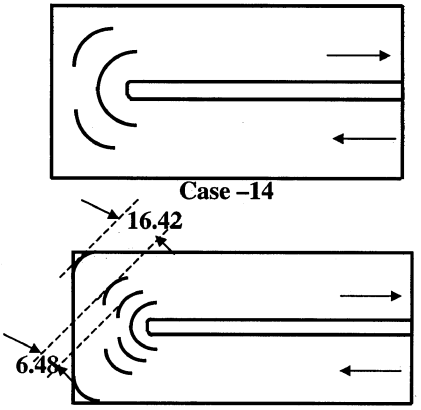

Case - 16

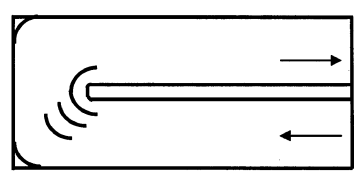

Case - 18

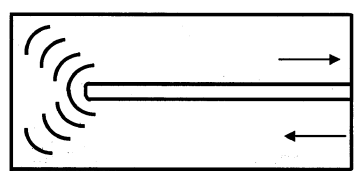

Case - 20

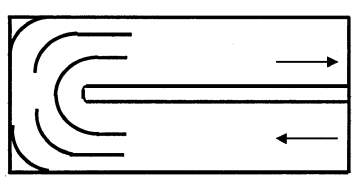

Case - 22

(b)

(a)

FIGURE 4

(a) Several test cases involving single short and long guide vane covered in this study. (b) Several test cases involving multiple guide vanes covered in this study.

reservoir. Water is pumped into the test section from the tank by a $0.4 \mathrm{~kW}$ centrifugal pump. Water flowing through the test section is recirculated to the tank. Gate valve ' $\mathrm{G} 2$ ' ' is used to adjust the volume flow rate of the water supplied to the testsection. Measurement of the volume flow rate is carried out by a rotameter ' $\mathrm{R}$ ' placed upstream of the test section. The test section is manufactured from a $0.0078 \mathrm{~m}$ thick perspex sheet cut, machined, and chemically bonded to form a channel of $0.029 \mathrm{~m}$ square cross section and $1.2 \mathrm{~m}$ length. A three-dimensional view of the test section is shown in Figure 2. Divider wall of thickness

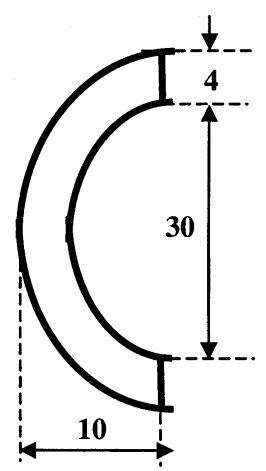

FIGURE 5

Short guide vane used in Cases 2, 4-8.

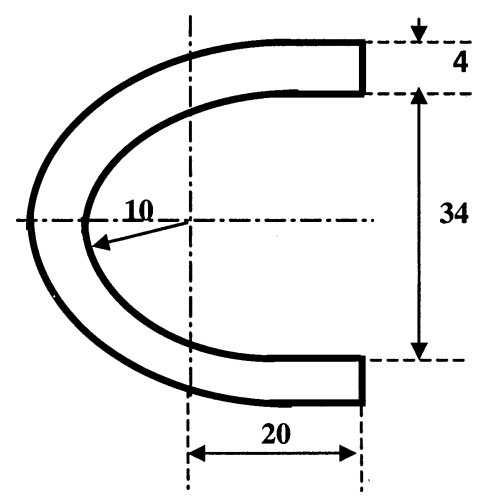

FIGURE 6

Long guide vane used in Cases 3, 9-12. 
TABLE 1

Turn Region Treatments

\begin{tabular}{|c|c|}
\hline Case No. & Description \\
\hline Case 1 & Without guide vane in the bend (base case). \\
\hline Case 2 & Short guide vane placed at the center of the bend (at origin ' $o$ '). \\
\hline Case 3 & Long guide vane placed at the center of the bend (at origin ' $o$ '). \\
\hline Case 4 & $\begin{array}{l}\text { Short guide vane shifted towards upstream outer surface by } 5 \mathrm{~mm} \text { (in the negative } y \text {-direction) from the center } \\
\text { of the bend. }\end{array}$ \\
\hline Case 5 & $\begin{array}{l}\text { Short guide vane shifted towards downstream outer surface by } 5 \mathrm{~mm} \text { (in the positive } y \text {-direction) from the center } \\
\text { of the bend. }\end{array}$ \\
\hline Case 6 & Short guide vane shifted towards end surface by $5 \mathrm{~mm}$ (in the negative $x$-direction) from the center of the bend. \\
\hline Case 7 & Short guide vane shifted towards end surface by $9 \mathrm{~mm}$ (in the negative $x$-direction) from the center of the bend. \\
\hline Case 8 & Short guide vane shifted towards divider tip by $5 \mathrm{~mm}$ (in the positive $x$-direction) from the center of the bend. \\
\hline Case 9 & Long guide vane shifted towards end surface by $5 \mathrm{~mm}$ (in the negative $x$-direction) from the center of the bend. \\
\hline Case 10 & Long guide vane shifted towards divider tip by $5 \mathrm{~mm}$ (in the positive $x$-direction) from the center of the bend. \\
\hline Case 11 & Long guide vane shifted upstream outer surface by $5 \mathrm{~mm}$ (in the negative $y$-direction) from the center of the bend. \\
\hline Case 12 & $\begin{array}{l}\text { Long guide vane shifted towards downstream outer surface by } 5 \mathrm{~mm} \text { (in the positive } y \text {-direction) from the center } \\
\text { of the bend. }\end{array}$ \\
\hline Case 13 & $\begin{array}{l}\text { Guide vane of } 90^{\circ} \text { included angle with } 14.5 \mathrm{~mm} \text { radius-Equispaced } 3 \text { vanes along each diagonal of the bend } \\
\text { (one vane acts as a fillet). }\end{array}$ \\
\hline Case 14 & $\begin{array}{l}\text { Guide vane of } 90^{\circ} \text { included angle with } 14.5 \mathrm{~mm} \text { radius-Equispaced two vanes along each diagonal of the bend } \\
\text { (no vane is present in the corner of the bend). }\end{array}$ \\
\hline Case 15 & $\begin{array}{l}\text { Guide vane of } 95^{\circ} \text { included angle with } 9.83 \mathrm{~mm} \text { radius }-3 \text { along each diagonal of the bend which are not equally } \\
\text { spaced (no vane is present in the corner of the bend). }\end{array}$ \\
\hline Case 16 & $\begin{array}{l}\text { Guide vane of } 95^{\circ} \text { included angle with } 9.83 \mathrm{~mm} \text { radius }-4 \text { along each diagonal of the bend which are not equally } \\
\text { spaced (one vane acts as a fillet). }\end{array}$ \\
\hline Case 17 & Same as Case 16 except that the two vanes on the upstream of the bend are removed. \\
\hline Case 18 & Same as Case 16 except that the two vanes on the downstream of the bend are removed. \\
\hline Case 19 & $\begin{array}{l}\text { Guide vane of } 95^{\circ} \text { included angle with } 9.83 \mathrm{~mm} \text { radius-Equispaced } 5 \text { vanes along each diagonal of the bend } \\
\text { (one vane acts as a fillet). }\end{array}$ \\
\hline Case 20 & $\begin{array}{l}\text { Guide vane of } 95^{\circ} \text { included angle with } 9.83 \mathrm{~mm} \text { radius-Equispaced } 4 \text { vanes along each diagonal of the bend } \\
\text { (no vane is present on the corner of the bend). }\end{array}$ \\
\hline Case 21 & Equally spaced one $180^{\circ}$ extended vane and two $90^{\circ}$ extended vane. \\
\hline Case 22 & as Case 21 except that fillet vanes are present in the corner. \\
\hline
\end{tabular}

(W) $0.0058 \mathrm{~m}$ is used. The turn clearance is kept equal to the channel width. The pressure drop is measured by a stationary U-tube differential manometer with carbon-tetrachloride as the manometric fluid. Figure 3 shows the static pressure tap locations on the top/bottom and outer surfaces.
Several turn treatments chosen for guiding the flow within the bend include short guide vane, long guide vane, and multiple guide vanes. Details of these configurations are given in Figures $4 \mathrm{a}$ and $4 \mathrm{~b}$. Figures 5 and 6 show the dimensions of the short and long guide vane configuration made of Perspex sheet.
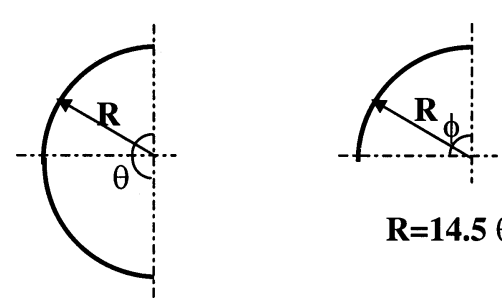

$$
\mathbf{R}=14.5 \theta=180^{\circ} \phi=90^{\circ}
$$

FIGURE 7

$90^{\circ}$ and $180^{\circ}$ vanes used in Cases 13 and 14 .

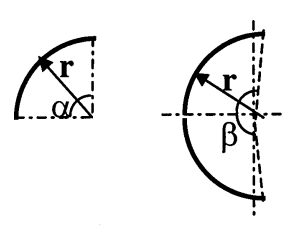

$\mathbf{r}=9.83 \alpha=9^{\circ} \beta=190^{\circ}$

FIGURE 8

$95^{\circ}$ and $190^{\circ}$ vanes used in Cases 15-20. 

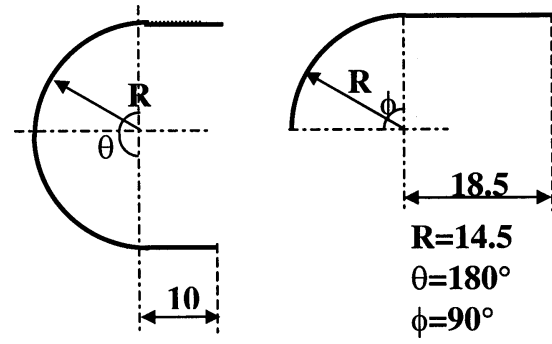

FIGURE 9

$90^{\circ}$ and $180^{\circ}$ extended vanes used in Cases 21 and 22.

Short and long guide vanes are placed in different locations within the bend region and corresponding cases include 2, 4-8 (short guide vane) and 3, 9-12 (long guide vane). A schematic of the short guide vane and long guide vane at various locations within the bend are shown in Figure 4a and Table 1. 180 and $90^{\circ}$ mild steel vanes of $14.5 \mathrm{~mm}$ radius (Figure 7) are placed within the bend in several combinations as in Cases 13 and 14 (Figure $4 \mathrm{~b}$ ). $190^{\circ}$ and $95^{\circ}$ mild steel vanes of $9.83 \mathrm{~mm}$ radius (Figure 8) are placed within the bend in several combinations as in Cases 15-20 (Figure $4 \mathrm{~b}$ ). $180^{\circ}$ and $90^{\circ}$ extended mild steel vanes of $14.5 \mathrm{~mm}$ radius (Figure 9) are placed within the bend in several combinations as in Case 21 (Figure 4b). Case 22 includes same vane configuration used in case 21 except the corners of
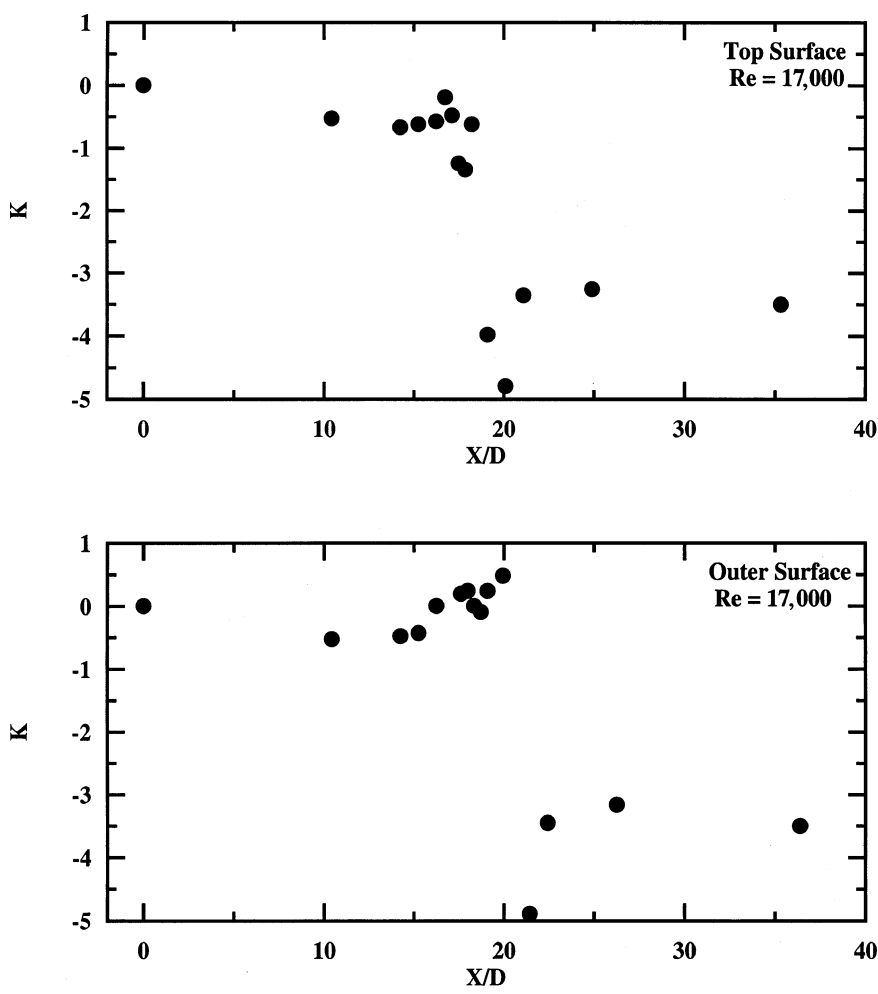

FIGURE 10

Top and outer surface pressure drop distribution without guide vane (base case). the bend are rounded by fillet vanes of radius $14.5 \mathrm{~mm}$ and $90^{\circ}$ included angle.

\section{DATA REDUCTION}

The local pressure drop is non dimensionalized by normalizing with the mainstream fluid dynamic pressure head as

$$
K=\frac{P_{X}-P_{i n}}{\left(\frac{1}{2}\right) \rho U^{2}}
$$

The overall mean pressure drop is the calculated difference between the arithmetic average values of pressure drop on the three surfaces (top surface, bottom surface, and outer surface) at the channel entrance and channel exit of the test section. This overall pressure drop is used to calculate the average friction factor given by

$$
f=\frac{P_{e x}-P_{i n}}{\left(\frac{1}{2}\right) \rho U^{2}\left(4 \frac{L}{D}\right)}
$$

The length ' $L$ ' is equal to the distance between the first tap ' $P_{\text {in }}$ ' and the last tap ' $P_{e x}$ ' of each test section. The average friction
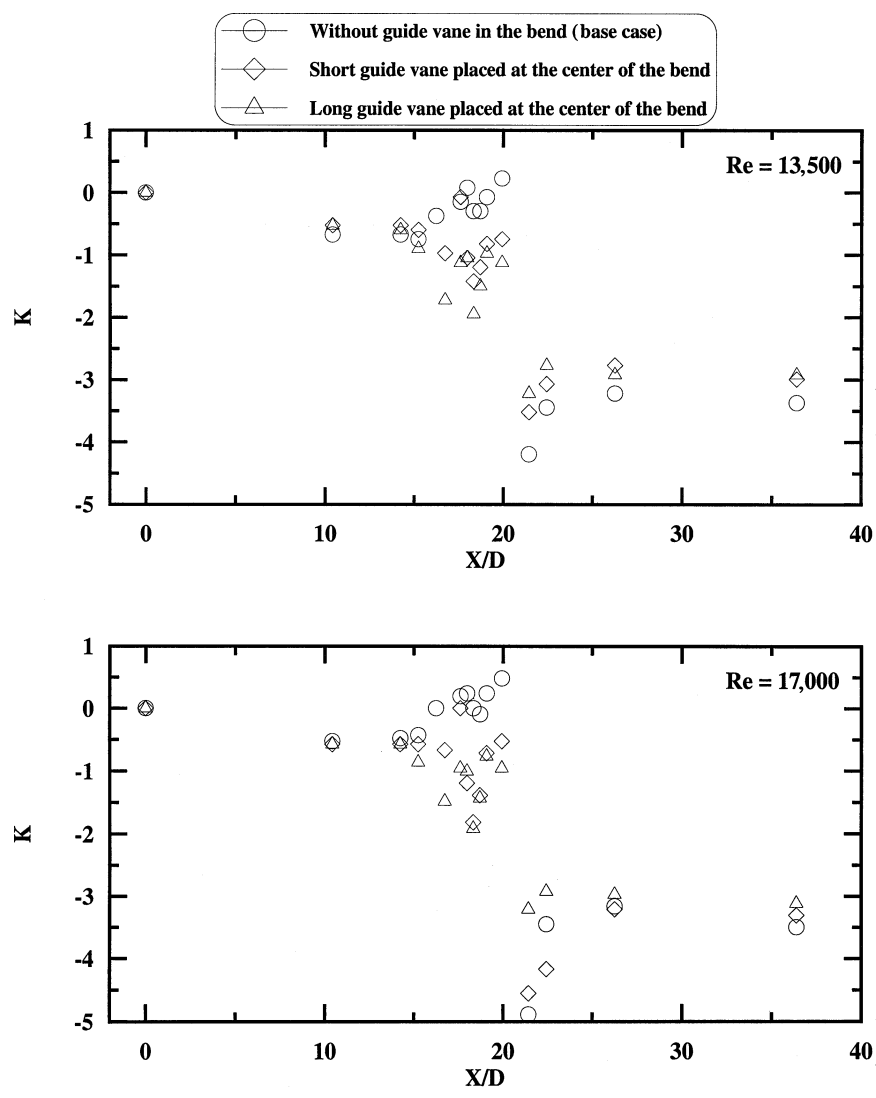

FIGURE 11

Outer surface pressure drop distribution with short and long guide vane in the center of the bend. 
factor is normalized by the friction factor for fully-developed turbulent flow in smooth circular tubes $(10000 \leq \operatorname{Re} \geq 100000)$ proposed by Blasius $\left(f / f(F D)=f /\left(0.046 \mathrm{Re}^{-0.2}\right)\right.$. The purpose of performing an uncertainty analysis is to estimate the uncertainty levels in the experimentally determined average friction factors. Uncertainties in parameters are estimated by using the root-sum-square method of Kline and McClintock (1953) and Taylor (1997). The measured quantity and its uncertainty can be expressed as $\mathrm{R}=\mathrm{R} \pm \delta \mathrm{R}$. The overall uncertainty assigned to a given measurement is the root sum square combination of the fixed error due to the instrumentation and random error observed during the running trials. The uncertainties of flow rate, hydraulic diameter, pressure drop, length of the test section, velocity of the flow, and average friction factor are estimated within $\pm 1 \%, \pm 1 \%, \pm 2 \%, \pm 0.03 \%, \pm 2.25 \%$, and $\pm 6 \%$, respectively.

\section{RESULTS AND DISCUSSIONS}

Figure 10 shows the local pressure drop distribution without any guide vane in the bend for top and outer surfaces with a
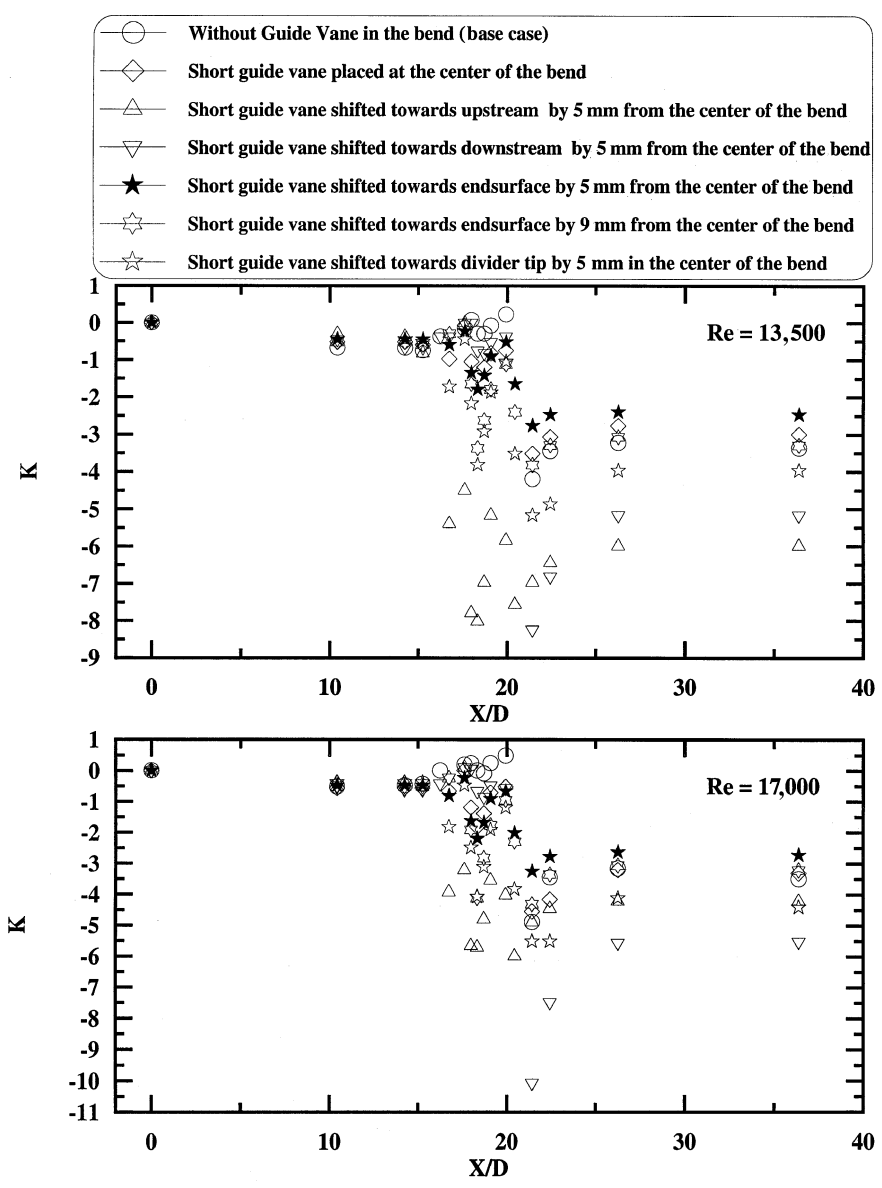

FIGURE 12

Outer surface pressure drop distribution with short guide vane at different locations within the bend.
Reynolds number of 17,000 . The pressure drop distribution on the top surface is identical as compared with that of the bottom surface. Hence, for the sake of clarity, only the top surface pressure drop distribution is shown in Figure 10. It was observed that local pressure drop distributions for Reynolds number 17,000 and 13,500 were identical. The pressure drop distribution without any guide vane is as follows.

Favorable pressure gradient in the upstream of the bend $(X / D=0-14.24$ along the outer and top surfaces), adverse pressure gradient in the upstream corner of the bend indicating a separated flow region in the upstream corner of the bend $(X / D=14.24-17.98$ on the outer surface and $X / D=14.24$ 16.74 on the top surface), mild pressure drop suggesting acceleration and convergence of the upstream surface flow toward the divider tip $(X / D=17.98-18.71$ on the outer surface and $X / D=$ $17.11-17.85$ on the top surface), adverse pressure gradient in the downstream corner of the bend suggesting separated flow region in the downstream corner of the bend $(X / D=18.71-19.94$ on the outer surface and $X / D=17.85-18.22$ on the top surface), large pressure drop in the downstream of the bend indicating an establishment of the radial inward wall surface flow downstream

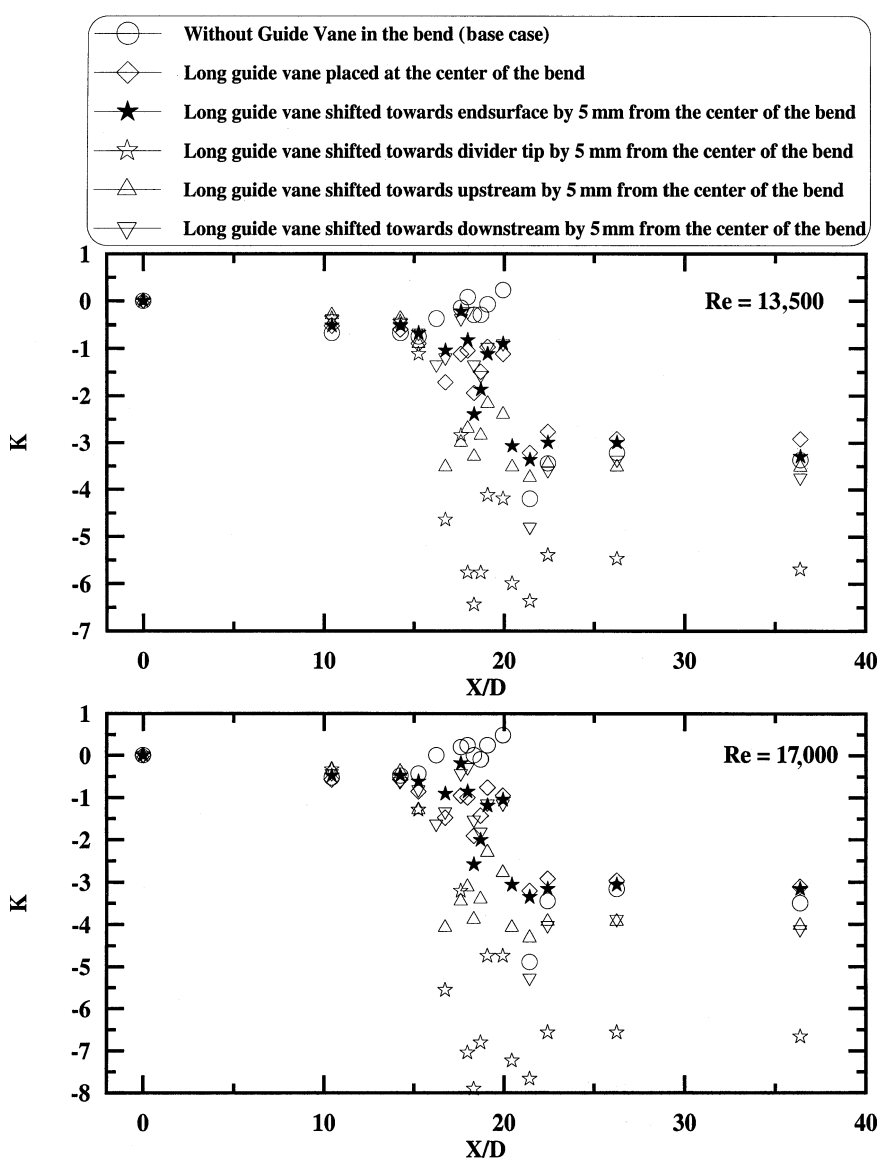

FIGURE 13

Outer surface pressure drop distribution with long guide vane at different locations within the bend. 
the bend $(X / D=19.94-21.44$ on the outer surface and $X / D=$ 18.22-20.09 on the top surface), adverse pressure gradient in the downstream of the bend indicating that the flow is reverting back to the fully developed condition $(X / D=21.44-26.27$ on the outer surface and $X / D=20.09-24.91$ on the top surface), and finally, favorable pressure gradient in the far downstream of the bend $(X / D=26.27-36.39$ on the outer surface and $X / D=$ 24.91-35.33 on the top surface). This pressure drop distribution is in line with the observations made by Metzger et al. (1984), Liou et al. (1999) and Son et al. (2002).

Figure 11 shows the effect of the presence of the short and long guide vanes placed in the center of a sharp cornered bend on the local pressure drop distribution for the outer surface at Reynolds numbers 13,500 and 17,000. Although the top and bottom surface pressure drop distributions were measured, they are not shown here because some of the static pressure taps get blocked due to of the presence of the guide vanes in the bend region. The local pressure drop distribution in the far upstream $(X / D=0-14.24)$ and downstream $(X / D=26.27-36.39)$ of the bend is unaffected by the presence of short and long guide vanes. Separation zones in the upstream and downstream corner of the bend and mild pressure drop in the middle of the bend continue to exist even in the presence of short and long guide vanes. In the downstream of the bend $(X / D=19.94-21.44)$, the sharp pressure drop in the presence of long guide vane is

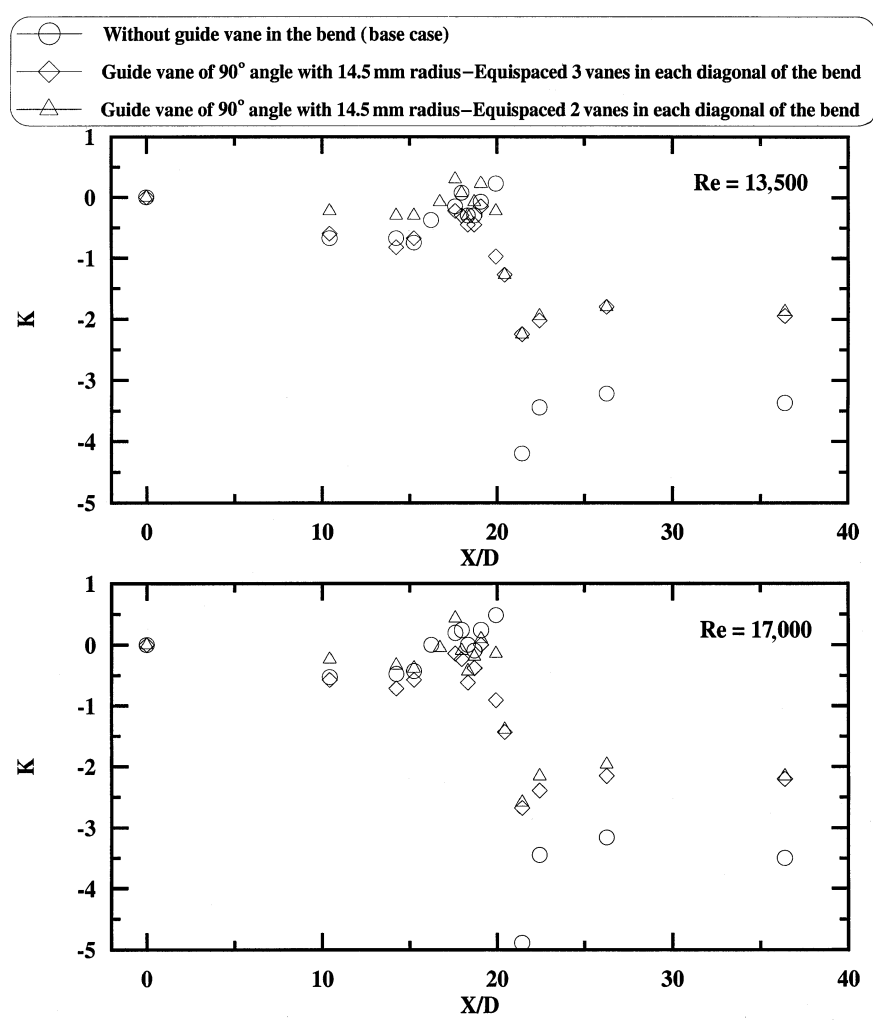

FIGURE 14

Outer surface pressure drop distribution with guide vanes of $90^{\circ}$ included angle with $14.5 \mathrm{~mm}$ radius. significantly less than that observed in base case and short guide vane situation. The overall pressure drop decreases by around $12 \%$ in the presence of long guide vane and only $5 \%$ in the presence of short guide vanes.

Figure 12 shows the effect of positioning the short guide vanes at various locations within the bend on the outer surface pressure drop distribution for Reynolds numbers 13,500 and 17,000. Adverse pressure gradients in the upstream and downstream corner of the bend and the overall pressure drop increase drastically by shifting the short guide vane towards either the upstream or downstream outer surface. Shifting the short guide vane towards the divider tip also results in an increase in the adverse pressure gradients and the overall pressure drop. However, shifting the short guide vane towards the end surface by $5 \mathrm{~mm}$ decreases the overall pressure drop by $25 \%$. Further shifting of the guide vane towards the end surface by $9 \mathrm{~mm}$ has no significant effect on the overall pressure drop. Hence, it may be concluded that shifting the short guide vane $5 \mathrm{~mm}$ towards the end surface profoundly reduces the overall pressure drop.

Figure 13 shows the effect of positioning the long guide vanes at various locations within the bend on the outer surface pressure drop distribution for Reynolds numbers 13,500 and 17,000. Adverse pressure gradients in the upstream and downstream corner of the bend and the overall pressure drop
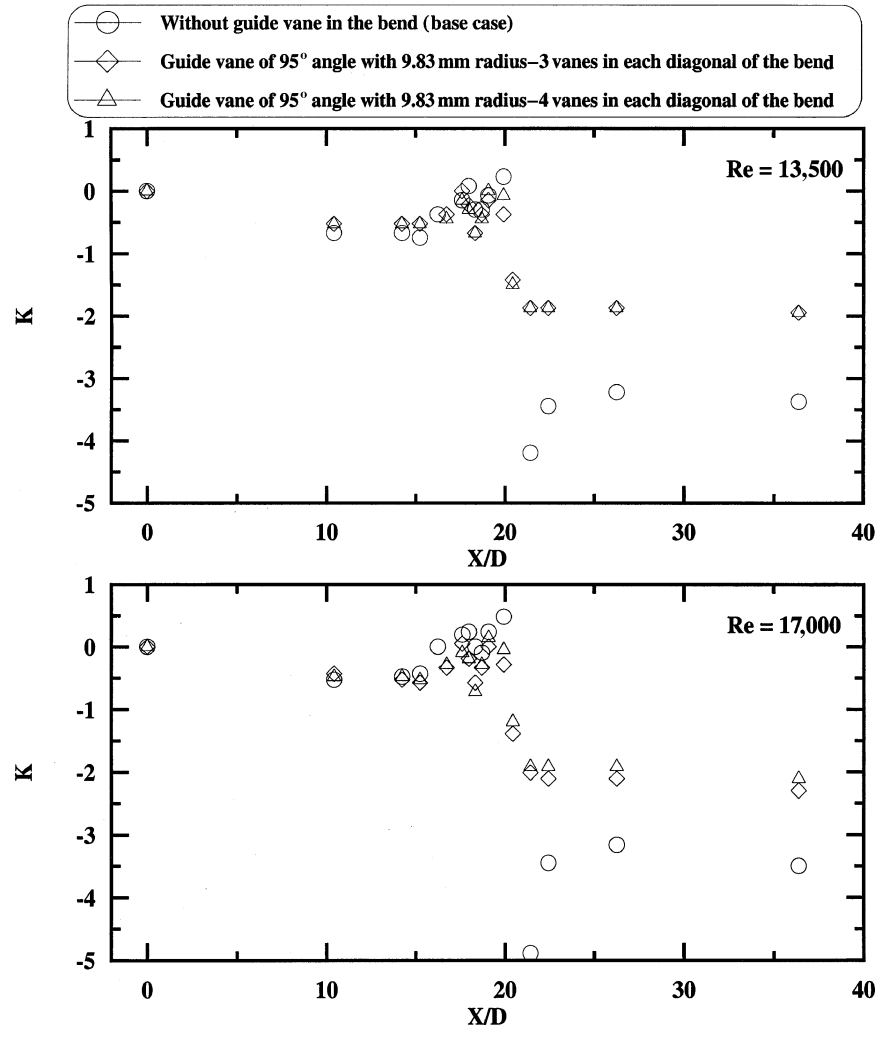

FIGURE 15

Outer surface pressure drop distribution with guide vane of $95^{\circ}$ included angle with $9.83 \mathrm{~mm}$ radius. 
increase drastically by shifting the long guide vane towards the divider tip. However, shifting the long guide vane towards the upstream and downstream surface increases the overall pressure drop marginally. The local pressure drop distribution of the bend with long guide vane at the center is similar to that of the situation in which the long guide vane is shifted towards the end surface by $5 \mathrm{~mm}$. Hence, no significant improvement can be achieved by shifting the long guide vane from the center.

Figure 14 shows effect of the number of vanes with $14.5 \mathrm{~mm}$ radius and an included angle of $90^{\circ}$ (Cases 13 and 14) on the local pressure drop distribution. These vanes are equally spaced along the diagonal of the bend. It can be seen that the overall pressure drop decreases by inserting the guide vanes by around $38-40 \%$. The insertion of the guide vanes has decreased the adverse pressure gradient zones in the downstream of the bend zone $(X / D=20.44-21.44)$. The local pressure drop distribution is not affected much by the number of vanes i.e., the pressure drop distribution for two vane situation and three vane situation are almost identical. Figure 15 shows the effect of the number of vanes with a radius of $9.83 \mathrm{~mm}$ and an included angle of $95^{\circ}$ (Cases 15 and 16) on the local pressure drop distribution. These vanes are not equally spaced along the diagonal of the bend. It can be seen that the overall pressure drop decreases by
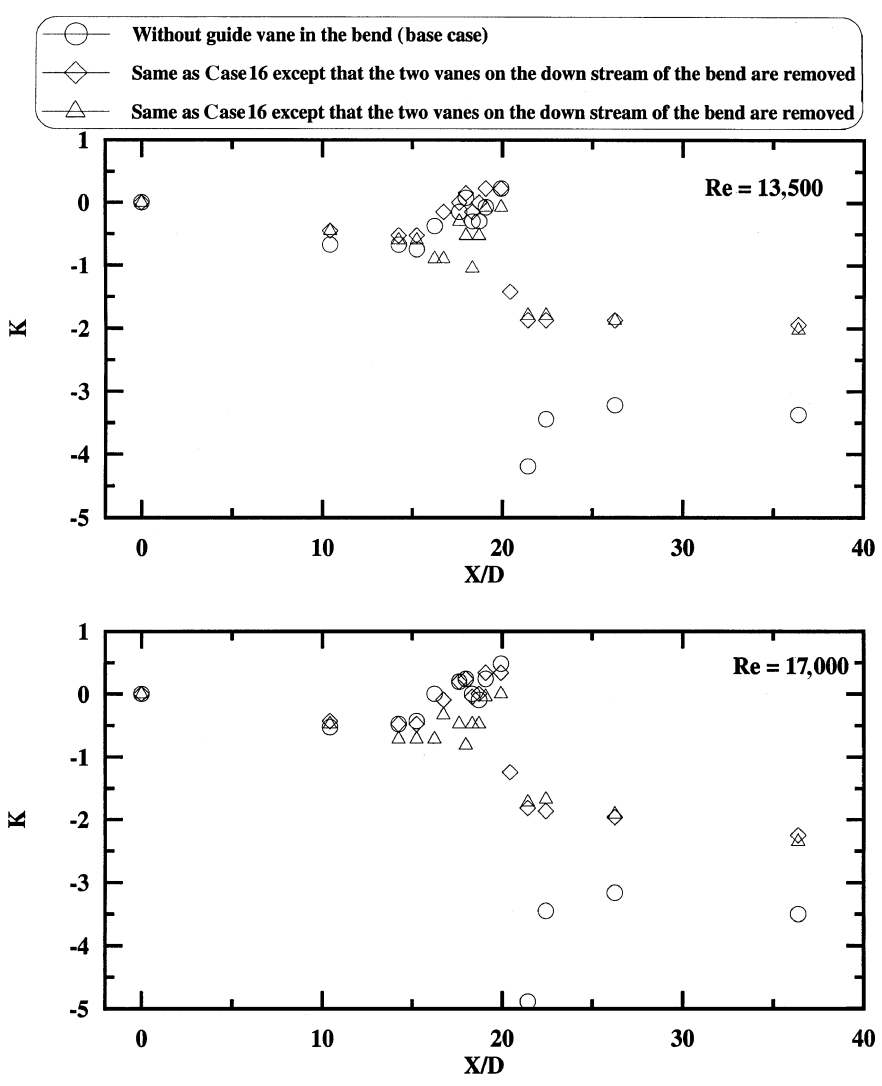

FIGURE 16

Outer surface pressure drop distribution with guide vane of $95^{\circ}$ included angle with $9.83 \mathrm{~mm}$ radius.

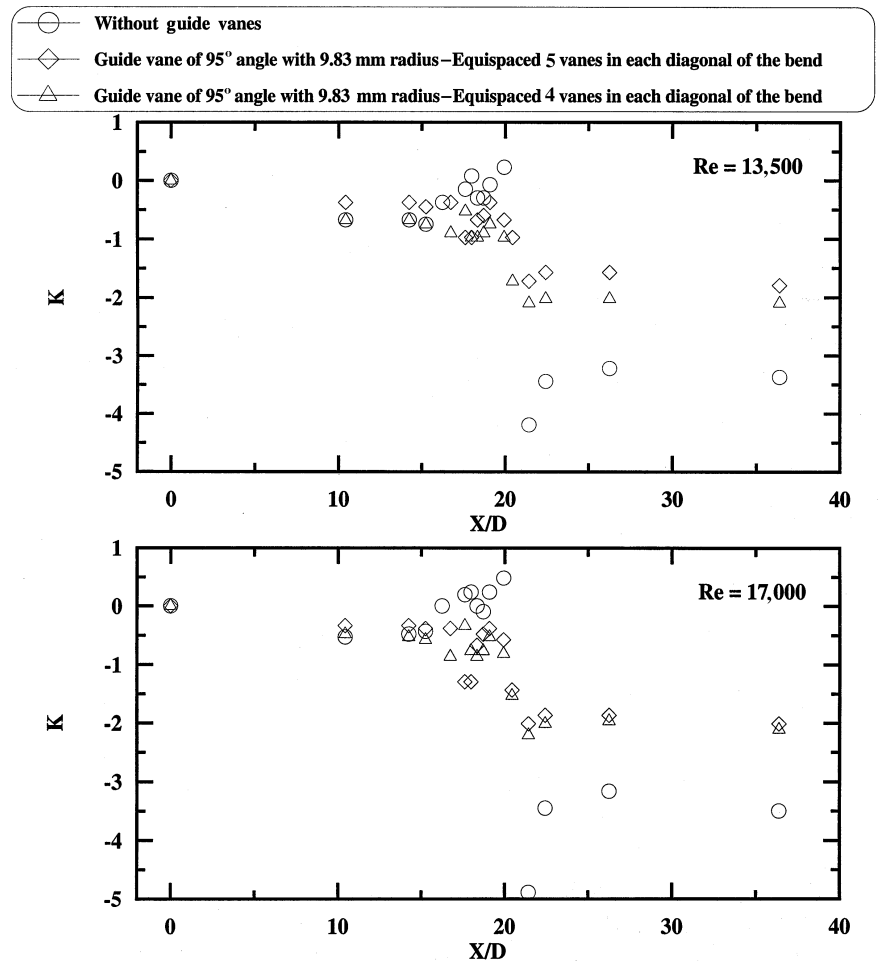

FIGURE 17

Outer surface pressure drop distribution with guide vane of $95^{\circ}$ included angle with $9.83 \mathrm{~mm}$ radius.
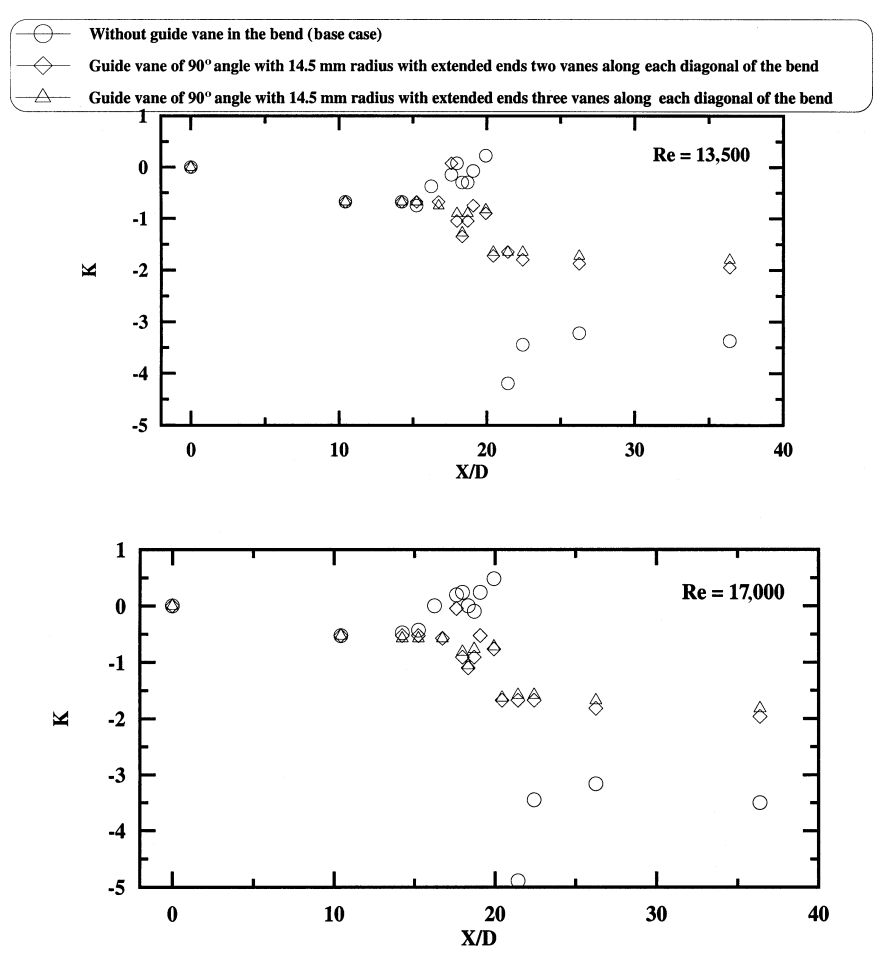

FIGURE 18

Outer surface pressure drop distribution with guide vane of $90^{\circ}$ included angle with $14.5 \mathrm{~mm}$ radius. 
TABLE 2

Average Friction Factor Ratio for All the Cases

\begin{tabular}{|c|c|c|c|c|}
\hline Case & $\begin{array}{c}\frac{f}{f(F D)} \text { for } \\
\operatorname{Re}=13,500\end{array}$ & $\begin{array}{l}\text { Reduction in the overall } \\
\text { pressure drop compared to the no } \\
\text { guide vane situation (percentage) }\end{array}$ & $\begin{array}{c}\frac{f}{f(F D)} \text { for } \\
\operatorname{Re}=17,000\end{array}$ & $\begin{array}{l}\text { Reduction in overall } \\
\text { pressure drop compared to the no } \\
\text { guide vane situation (percentage) }\end{array}$ \\
\hline No guide vane (Case 1) & 3.231 & - & 3.731 & - \\
\hline 2 & 3.106 & 3.86 & 3.492 & 6.4 \\
\hline 3 & 2.876 & 11 & 3.253 & 12.8 \\
\hline 4 & 3.887 & -20 & 4.463 & -19.63 \\
\hline 5 & 5.013 & -55.14 & 5.878 & -57.53 \\
\hline 6 & 2.469 & 24 & 2.741 & 26.53 \\
\hline 7 & 3.309 & -2.4 & 3.596 & 3.61 \\
\hline 8 & 4.099 & -27 & 4.668 & -25.1 \\
\hline 9 & 3.360 & -4 & 3.476 & 6.822 \\
\hline 10 & 5.599 & -73.3 & 6.967 & -86.722 \\
\hline 11 & 3.538 & -7.5 & 4.361 & -16.913 \\
\hline 12 & 3.767 & -16.59 & 4.395 & -17.81 \\
\hline 13 & 1.986 & 38.5 & 2.317 & 38 \\
\hline 14 & 1.858 & 42.5 & 2.231 & 40.2 \\
\hline 15 & 1.986 & 38.54 & 2.453 & 34.3 \\
\hline 16 & 2.037 & 36.95 & 2.214 & 41 \\
\hline 17 & 1.986 & 38.54 & 2.402 & 36 \\
\hline 18 & 2.165 & 33 & 2.539 & 32 \\
\hline 19 & 1.781 & 44.86 & 2.215 & 40.62 \\
\hline 20 & 2.138 & 33.82 & 2.249 & 40 \\
\hline 21 & 1.934 & 40.12 & 2.095 & 44 \\
\hline 22 & 1.833 & 43.27 & 1.942 & 48 \\
\hline
\end{tabular}

inserting the guide vanes by around $35-40 \%$. Unlike the no guide vane situation, no adverse pressure gradient zone is observed in the immediate downstream region of the bend $(X / D=20.44$ 21.44). Figure 16 shows the effect of removal of two middle vanes of radius $9.83 \mathrm{~mm}$ and included angle of $95^{\circ}$ (Cases 17 and 18) on the local pressure drop distribution. The overall pressure drop has not been affected, in spite of removal of middle vanes in the upstream side. However, the decrease in the overall pressure decreases by removing the middle vanes in the downstream side by around $32-38 \%$.

Figure 17 shows the effect of a number of equally spaced vanes of radius $9.83 \mathrm{~mm}$ and an included angle of $95^{\circ}$ (Cases 19 and 20). It can be observed that the adverse pressure gradient zone in the downstream of the bend is not present and the overall pressure drop has decreased compared to that of the base case by around $34-45 \%$. Placing of the vanes in the fillet has no appreciable effect on the overall pressure drop. Figure 18 shows the effect of $90^{\circ}$ and $180^{\circ}$ extended vanes of radius $14.5 \mathrm{~mm}$ with and without fillet vanes in the corner (Cases 21 and 22). It can be observed that the overall pressure drop decreases by around $40-45 \%$ by inserting $180^{\circ}$ vanes. However, the three guide vane situation (Case 22) has less adverse pressure gradient zones in the upstream zone of the bend compared to that of the two guide vane situation (Case 21).
The average friction factor ratio for all the cases covered in this study is summarized in the Table 2. Friction factor ratio observed at a Reynolds number of 13,500 is consistently less than that of Reynolds number 17,000. In general, there is a decrease in the overall pressure drop because of the presence of the guide vanes. Maximum decrease in the overall pressure drop that could be attained by using a single short guide vane is around $25 \%$. However, by inserting multiple guide vanes along the diagonal of the bend decreases the overall pressure drop by as much as 44-48\%. Out of all the cases studied, Case 22 results in the least overall pressure drop. However, Cases 14, 16, 19, and 21 result in a decrease of overall pressure drop by $40-44 \%$.

\section{CONCLUSIONS}

An experimental study is conducted to investigate the effect of the turn treatments like single guide vane (short and long) and multiple guide vane located at different positions within a bend on the local and overall pressure drop distribution in a square cross-sectioned smooth channel with a sharp $180^{\circ}$ bend. The study is carried out for a divider wall thickness to hydraulic diameter $(W / D)$ of 0.2 for Reynolds numbers of 13,500 and 17,000 . Long guide vane placed at the center of the bend results in a large decrease of overall pressure drop (12\%) compared 
to that of the short guide vane placed at the center of the bend $(5 \%)$. Shifting the long guide vane in any position other than the center of the bend results in the increase in the overall pressure drop. Shifting the short guide vane towards the end surface by $5 \mathrm{~mm}$ results in a decrease in the overall pressure drop by $25 \%$. Other than this position, the shifting of the short guide vane to any other position within the bend results in only an increase in the overall pressure drop. Multiple guide vanes of different radii (9.83 $\mathrm{mm}$ and $14.5 \mathrm{~mm})$ and different included angles $\left(90^{\circ}, 95^{\circ}\right.$, and $180^{\circ}$ ) are studied. Multiple guide vanes of any configuration covered in this study are better than the single guide vane (short and long). A combination of $90^{\circ}$ and $180^{\circ}$ extended vanes along with fillet vanes in the corner of the bend result in a maximum decrease of overall pressure drop (around 43-48\%). Hence, Case 22 is recommended for the optimum pressure drop.

\section{NOMENCLATURE}

$D \quad$ hydraulic diameter (m)

$f \quad$ average friction factor (Equation 2)

$f(F D)$ fully developed friction factor in smooth circular tubes $g \quad$ acceleration due to gravity $\left(\mathrm{m} / \mathrm{s}^{2}\right)$

$K \quad$ nondimensional pressure drop (Equation 1)

$L \quad$ length of the test section (m)

$P_{i n} \quad$ static pressure at channel entrance $(\mathrm{Pa})$

$P_{X} \quad$ static pressure at an axial distance from channel entrance $(\mathrm{Pa})$

$P_{e x} \quad$ static pressure at the channel exit $(\mathrm{Pa})$

$\operatorname{Re} \quad$ reynolds number $(\rho U D / \mu)$
$U \quad$ average velocity in flow channel $(\mathrm{m} / \mathrm{s})$

$W \quad$ divider wall thickness (m)

$X \quad$ axial distance from the channel entrance (m)

$\rho \quad$ density of water $\left(\mathrm{kg} / \mathrm{m}^{3}\right)$

$\mu \quad$ dynamic viscosity of water (Pa.s)

\section{REFERENCES}

Ekkad, S., and Han, J. C. 1997. Detailed heat transfer distributions in two pass square channels with rib turbulators. International Journal of Heat and Mass Transfer 40:2525-2537.

Kline, S. J., and McLintock, F. A. 1953. Describing uncertainties in single sample experiments. Mechanical Engineering 75:3-8.

Liou, T. M., and Chen, C. C. 1999 . Fluid flow in a $180^{\circ}$ sharp turning duct with different divider thicknesses. ASME Journal of Turbomachinery 121:569-576.

Metzger, D. E., and Plevich, C. W. 1990. Effects of turn region treatments on pressure loss through sharp $180^{\circ}$ bends. Proceedings of Third International Symposium on Transport Phenomena and Dynamics of Rotating Machinery (ISROMAC-3) 301-312.

Metzger, D. E., Plevich, C. W., and Fan, C. S. 1984. Pressure loss through sharp $180^{\circ}$ turns in smooth rectangular channels. ASME Journal of Engineering for Gas Turbine and Power 106:677681.

Son, S. Y., Kihm, K. D., and Han, J. C. 2002. PIV flow measurements for heat transfer characterization in two pass square channels with smooth and $90^{\circ}$ ribbed walls. International Journal of Heat and Mass Transfer 45:4809-4822.

Taylor, J. R. 1997. An introduction to error analysis-The study of uncertainties in physical measurements. Second Edition, Sausalito, CA: University Science Books. 

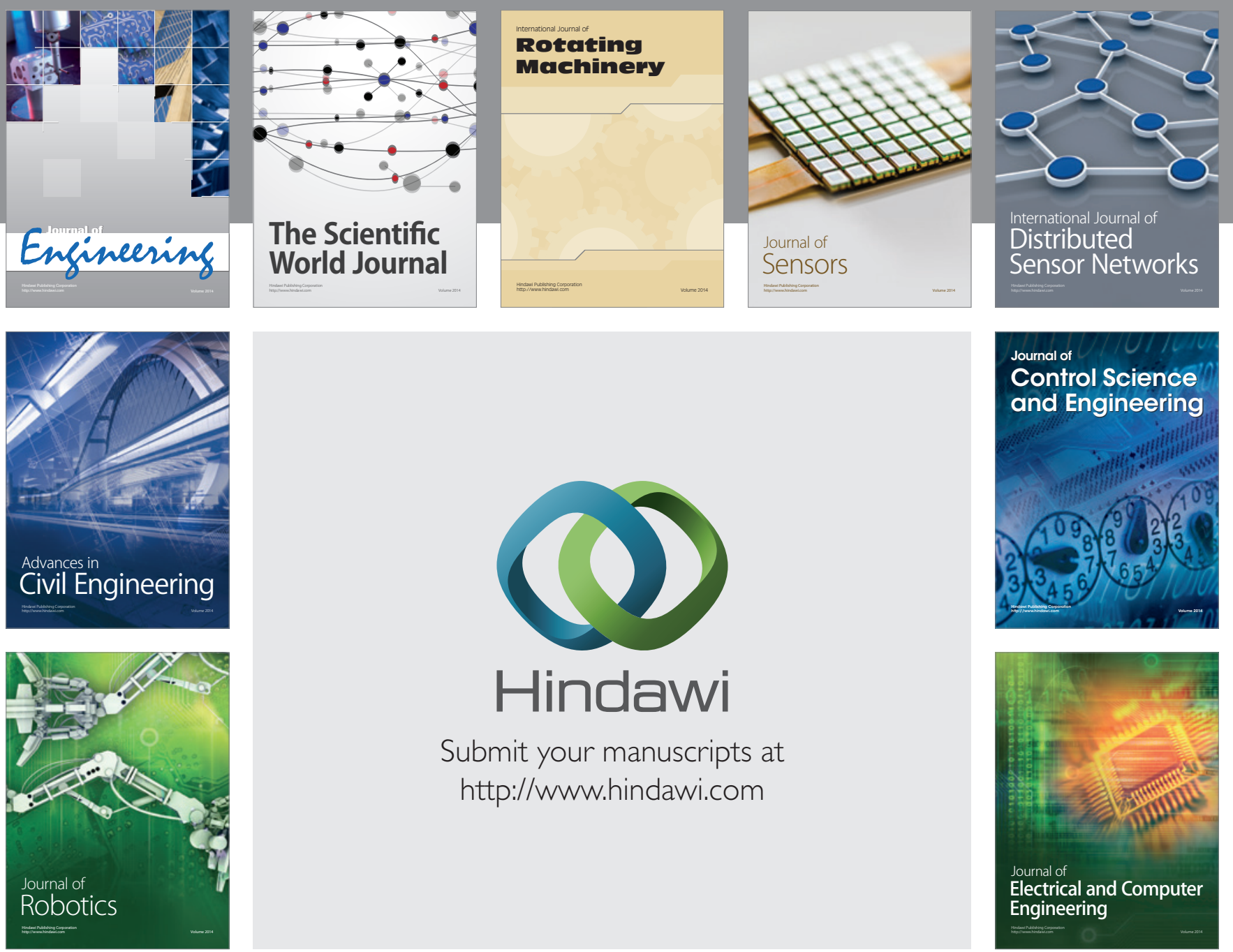

Submit your manuscripts at

http://www.hindawi.com
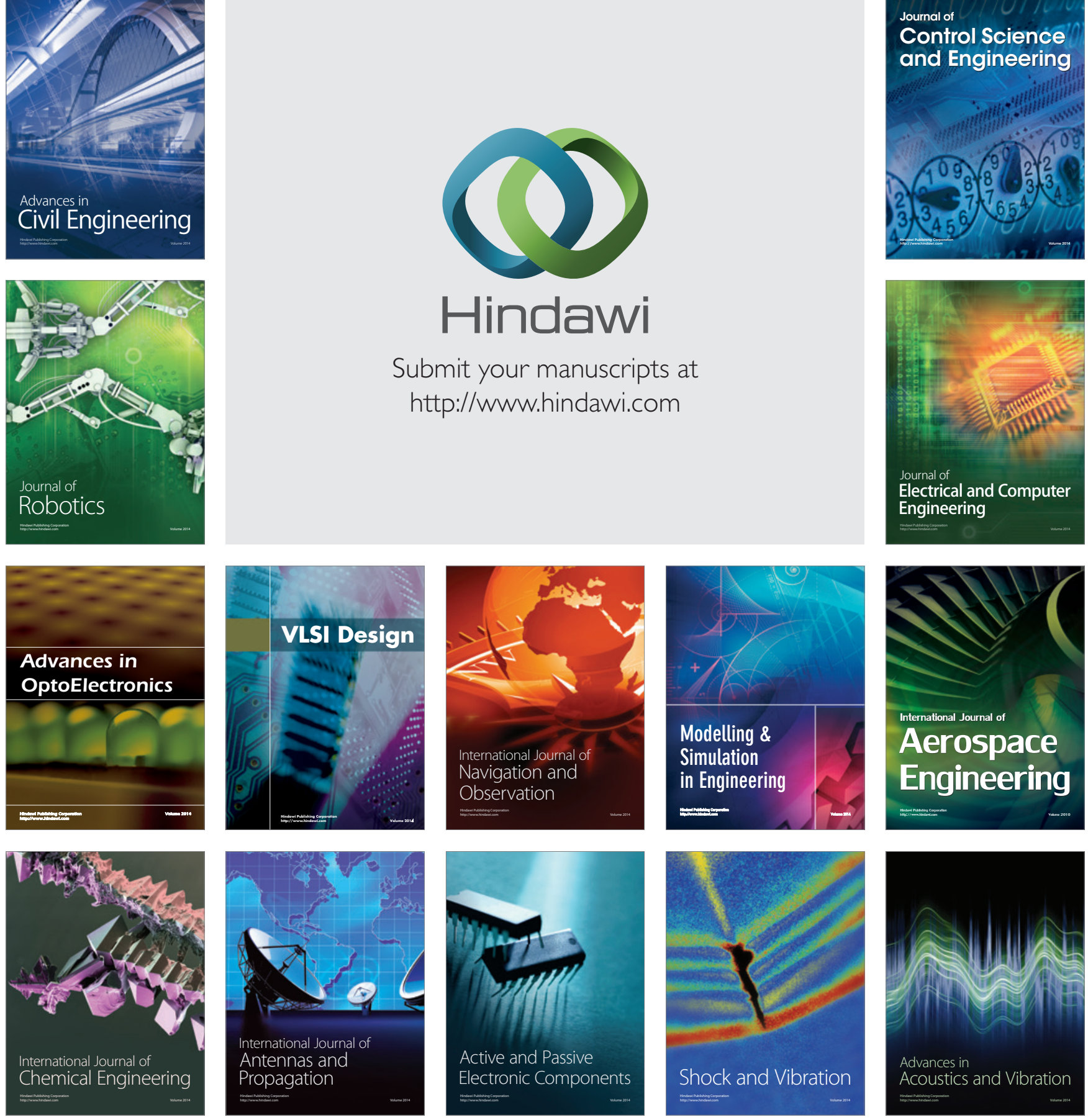